\title{
Technological innovation in health: back to origins
}

\section{Ariane Ferreira Machado Avelar' ORCID: 0000-0001-7479-8121 \\ Luciano Marques dos Santos" ORCID: 0000-0001-7866-6353}

' Universidade Federal de São Paulo, Departamento de Enfermagem Pediátrica. São Paulo, São Paulo, Brazil. "Universidade Estadual de Feira de Santana, Departamento de Saúde. Feira de Santana, Bahia, Brazil.

How to cite this article: Avelar AFM, Santos LM. Technological innovation in health: back to origins.

Rev Bras Enferm. 2021;74(Suppl 5): e74Suppl501. https://doi.org/10.1590/0034-7167.202174Suppl501
Technological innovation in health refers to the application of scientific and technological knowledge to solve problems that arise in different sectors and that impact changes in the diagnosis, treatment and prognosis of assisted individuals, with cost reduction, professional assistance and improvement in the care process ${ }^{(1)}$.

To be positively assessed, technological innovation in health must present a balance between the associated costs and the impact on quality of care, as well as on its social value, in a tangible and non-tangible way, from results to the health of individuals, families, and communities, satisfaction and professional growth, in addition to benefits for the institution and health system.

Thinking about technological innovation in health and, more specifically, in nursing, leads us to the daily activities developed by professionals to achieve the best results for individuals and their families who receive care. The conditions experienced in healthcare, whether in hospitals, outpatients, at home or in the community, encompass a variety of situations, experiences and knowledge, which constitute inexhaustible sources of resources for constant technological innovation.

It is important that healthcare is understood as a technology, defined as the art, skill, method, way, way of doing, the ratio between knowing and doing, and that any advance or adaptation for care the needs of individuals and their families are perceived and valued as an innovation that provides the achievement of improvements in the living and health conditions of a person who experiences changes in their health-disease process.

Therefore, technologies will be needed that refer us to individuals' essential needs, bringing the environment as the main technological framework for promoting and restoring health, starting from the principles proposed by Florence Nightingale that, for the establishment of health and cure, we must offer individuals the best conditions for nature to act on them ${ }^{(2)}$.

Often, the term technological innovation is understood as the development or implementation of equipment with new attributes developed based on unsuccessful experiences and that propose the resolution of problems. However, technological innovation in health is much more than that, as it comprises the identification of the need or problem to be solved, the knowledge of professionals who guide the new alternative for resolving the issue and creativity, which favors the finding of alternatives based on professional and human experience, favoring the proposal of individualized care in the face of identified demands.

Although many technological innovations require endless financial resources for development and acquisition, it is possible to propose measures that innovate care without increasing costs for the institution or for patients and families. Thus, allowing newborns to remain in skin-to-skin contact after birth, subjecting hospitalized individuals to the light and dark cycle, reducing manipulation and noise at night to promote sleep, among other aspects, they constitute technological innovations in care, and although they are important and have a profound impact on the maintenance and restoration of health, they are largely neglected in healthcare settings. 
What does it matter to have several highly specialized technological resources if the origin of care is not prioritized? How can innovative equipment and technologies work effectively in conditions that are not conducive to restoring health? What is the use of having the latest equipment if we do not have professionals capable of identifying the basic human needs of individuals?

Thus, technological innovation in current times refers to the return to the origin, to what individuals present in their essence, either respecting their individuality and identifying their priorities, or allowing professionals who perform care to implement the most different facets of technological innovation, based on in scientific, ethical knowledge, in planning, in professional, personal experiences and attention to the specific demands of each individual under their care, so that the main technological advances in equipment, drugs and therapies can exercise their functions in an individual placed in the best conditions for their recovery.

We need to go back to the essence of care for human beings, not denying the technological advances that greatly contribute to restoration of health and meet the most different and complex dimensions and demands, but bringing to light the best conditions of care for individuals and families, so that every investment can have an effect and, mainly, with the reduction of damages arising from the exacerbated use of technological innovations that can sustain life, but does not guarantee its quality.

Therefore, despite the frequent innovations in the field of health based on scientific evidence and, in general, result in important potential benefits to people $e^{(3)}$, it becomes essential to overcome the barriers that prevent its dissemination and use in daily clinical practice so that its impact reaches greater dimensions of human experience.

\section{REFERENCES}

1. Blanch L, Guerra L, Lanuza A, Palomar G. Innovation and technology transfer in the health sciences: a cross-sectional perspective. Med Intensiva. 2014;38(8):492-7. https://doi.org/10.1016/j.medin.2014.04.012

2. Davies R. Notes on nursing: what it is and what it is not. (1860): By Florence Nightingale. Nurse Educ Today. 2012;32:624-6. https://doi. org/10.1016/j.nedt.2012.04.025

3. Guimarães R. Política de Ciência, Tecnologia e Inovação em Saúde. Ciênc Saúde Colet. 2019;24(3):881-6. https://doi. org/10.1590/1413-81232018243.34652018 